\title{
Which elements were significant in reducing obstetric anal sphincter injury? A prospective follow-up study
}

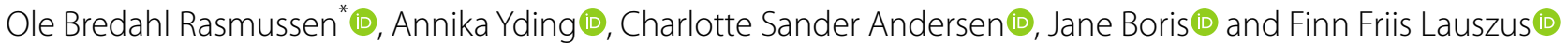

\begin{abstract}
Background: To examine which elements of an obstetric anal sphincter injury (OASI) care bundle were protective for OASI. Several interventional trials showed that application of a care bundle involving a hands-on approach to perineal protection may reduce the risk of OASI. Previously, we found that only the element "hand on the fetal head" in itself was protective, although the risk of a type 2 error was calculated to be $50 \%$.

Methods: A prospective follow-up study in an obstetric department in Denmark with 3200 deliveries per year. We included a cohort of 10,383 women giving birth vaginally from gestational week $22+0$ from 2016 through 2019. We documented on a person-level the five elements of the care bundle together with maternal and obstetrical characteristics. The elements were 1) communication, 2) visible perineum, 3) hand on fetal head, 4) perineal support and 5) certification. Regression analysis was used for analysis of associations. The primary outcome measure was OASI.
\end{abstract}

Results: The total rate of OASI in vaginally delivering women was $1.9 \%$. The incidence was $3.2 \%$ in nulliparous women giving birth vaginally. The rate of cesarean section was $16.5 \%$ and for episiotomy $2.4 \%$. The reduction in the incidence of OASI was sustained since 2013. Hand on the fetal head and perineal support both were protective factors for OASI. In case of a nulliparous woman with a neonate weighing $3500 \mathrm{~g}$ giving birth spontaneously, the relative risk (RR) for OASI was 0.50 ( $95 \% \mathrm{Cl}$ 0.49- 0.51) with use of hand on the fetal head together with perineal support against no use. Similarly, with a nulliparous woman giving birth to a neonate of $3500 \mathrm{~g}$ by vacuum extraction, the RR for OASI was 0.65 (95\% $\mathrm{Cl}$ 0.62-0.68) against no use.

Conclusions: Both hand on the fetal head and perineal support were associated with a reduced risk of OASI.

Keywords: Obstetrics, Obstetrical anal sphincter injury, Perineum, Hands-on, Hands-off, Delivery

\section{Background}

Obstetric anal sphincter injury (OASI) is a serious complication of vaginal delivery. The severity of OASI is documented $[1,2]$ and confirmed by organizations representing women, such as "Mothers with Anal Sphincter Injuries in Childbirth" [3]. Suffering from an OASI is a strong risk factor for a negative birth experience [4].

*Correspondence: oleramus@rm.dk

Department of Obstetrics \& Gynecology, Herning Hospital, Gl. Landevej 61,7400 Herning, Denmark
Several interventional trials show that application of a care bundle involving a hands-on approach to perineal protection may reduce the risk of OASI [5-11]. Furthermore, several trials find that improved results with these interventions may be sustainable [12-14]. In one program, the specific use of manual perineal protection is documented and a protective effect found [15].

Previously, we showed that only the element of having a hand on the fetal head resulted in a statistically and clinically significant reduction in OASI [16], albeit the analysis as an exploratory pilot study was carried out on 
a modest-sized cohort; thus, the risk of a type 2 error was calculated to be $50 \%$.

We aimed at analyzing the individual elements of an OASI care bundle including episiotomy and several known risk factors in a large cohort. Even though episiotomy may be viewed as a grade 2 laceration in itself, there is the potential that its use may reduce the risk of OASI [17]. Moreover, we wished to examine the sustainability over several years of the OASI care bundle. In general, a care bundle is meant to be implemented as a whole [18]. However, this may be complex in daily practice at a birth department since the ideal situation is not always present where all elements of the care bundle can be applied. Acute situations and specific birth positions and wishes by the woman giving birth may prevent the use of all elements. For this reason, we wished to analyze which separate elements of the care bundle were protective in order to provide evidence for a more thorough understanding of the value of each of the involved elements of the care bundle. In the broader perspective, there is a need for OASI research to focus more on delivery procedures and not restricting risk analyses to individual data on the woman or the infant [7].

\section{Methods}

\section{Intervention}

The present follow-up study arose from a quality improvement project that began in June 2013 at the delivery ward in Herning Hospital, Denmark in which we successfully reduced the incidence of OASI from 7.0 to $3.4 \%$ in vaginally delivering nulliparous women [9]. In this project, we implemented five elements of an OASI care bundle: 1) Communication settled; i.e. a shared decision with the woman, for instance about birth position and about not to push when the head is crowning; it is considered essential for complying with this element that the woman is explained about the intervention, understands the implications and confirms the use in the context of a shared decision making; the discussion and decision should preferably take place during pregnancy, but it may also take place during the first stage of labor; 2) Visible brim of the perineum during delivery of the fetal head in order to facilitate a view of perineum and the best possible application of hand on the fetal head and perineal support; 3) Whole hand on the fetal head as opposed to only using three fingers in order to slow down the speed of delivery when the head is crowning; 4) Perineal support during delivery of the head giving a firm support to perineum whilst simultaneously facilitating the naturally occurring extension of the head; 5) Certification of midwives, midwife-students and obstetricians to the OASI care bundle. The certification process is standardized using a power point presentation as a common starting point for introduction to the project and for further discussion. Furthermore, midwives practice the hands-on technique on a childbirth simulator and afterwards have three supervised births. Doctors practice operative vaginal deliveries on a childbirth simulator. Midwife supervisors are responsible for going through the introduction to the intervention and the certification process.

All women were included who gave birth vaginally in our department or at home with support by a midwife from our department from gestational age $22+0$ in 2016 through 2019.

\section{Setting}

In our ward we have approximately 3200 deliveries per year from gestational week $28+0$. Very preterm births before this gestational age are transferred to a nearby university hospital at Skejby whenever feasible. Ninety full-time midwives and 20 doctors are working in our department. Information is given to the pregnant woman about what may be done to reduce the risk of OASI in consultations with the midwife in gestational week 29 . A shared decision-making takes place about giving birth including preferred treatment of pain from contractions, birth position etc. In our department, instructions for midwives and doctors are that the naturally occurring extension of the head should be supported when the head is delivered through the introitus during spontaneous vaginal delivery (SVD) and operative vaginal delivery (OVD). In case of OVD, we use a vacuum extractor and we advocate that OVD is done as a team work with a midwife supporting the perineum while the doctor performs the extraction. Communication is maintained with the woman at all times. When the fetal head is crowning the doctor controls the speed of delivery using one hand on the extractor while the other regulates the necessary force and direction of the pull. Episiotomy is either by medio-lateral or by the lateral method. The latter is recommended in our department.

\section{Data collection}

Information from each birth was entered into the electronic maternity records immediately after birth by the attending midwife. This included the use of each of the five elements of the care bundle. There was no registration of the time that each of the elements were applied. Satisfaction with the birth experience was recorded from September 2016 on a visual analogue scale from 1 to 10 where 10 is the highest level of satisfaction. The registration was carried out within the first couple of days after delivery. From December 2017 we started documenting birth position. 


\section{Outcomes}

The primary outcome was OASI, which comprises grade 3 and 4 anal sphincter injury according to the international classification used in our department for several years [19]. The attending midwife examines the perineum of the woman immediately postpartum including a digital rectal examination. Whenever the midwife suspects an OASI, a doctor is called to confirm the diagnosis. A midwife examines all women within 3 days postpartum to see how the tears are healing. In case of a missed OASI, a doctor changes the diagnosis accordingly. Women with an OASI receive follow-up care by a specialized midwife, physiotherapist and the gynecology clinic.

\section{Statistical analysis}

Compared with the initial project we wanted to reduce the risk of a type- 2 error and aimed at halving the variance. This meant that we needed at least four times the size of the population compared with the initial cohort of 1622 nulliparous women. Thus, all women giving birth vaginally from gestational week $22+0$ from January 2016 through December 2019 were included in the cohort.

Statistics were performed with IBM SPSS Statistics 24. The difference between two means was tested with Student's t-test if data followed Gaussian distribution; otherwise, Mann-Whitney's test was used. $\chi^{2}$ - test was used for categorical variables. Categorical variables were analyzed separately and by 5 elements present and absent combined. When the continuous variables age, gestational age, birth weight were categorized they were analyzed combined and for trend for linear association. Relative risk (RR) of OASI was calculated from a chosen baseline and stated with 95\% confidence intervals (CI). Regression analysis was performed with OASI as dependent variable. Linear regression was used on the continuous variables age and birth weight and logistic regression on parity, the five elements individually (communication, visible perineum, hand on the fetal head, perineal support, certification), all five elements present (all-or-none), epidural analgesia, oxytocin drip, episiotomy, and vacuum delivery as they are dichotomous. All independent variables were tested individually against OASI and those with significant results and all five elements separately were added to a full model. Separate analyses were performed on all five elements present versus not all five elements present at birth. For multiparous women previous cesarean was added to the full model with all five elements individually. A two-sided $p<.05$ was the level of significance. Values are given as mean \pm SD if Gaussian distributed or otherwise stated. We have adhered to the STROBE guideline when reporting this study.

\section{Results}

During the 4 years, 12,429 women gave birth to 12,548 infants. The number of cesarean sections (CS) was 2047 resulting in a total rate of $16.5 \%$ with $17.3 \%$ in nulliparous women and $15.9 \%$ in multiparous $(p<0.04)$. From the total group we received feedback on birth experience from 6528 women; thus, the response rate was $61 \%$. Satisfaction with birth experience was rated between 8 and 10 by $98 \%$. In the group of vaginally delivering women, the rate of Apgar score $<7 / 5 \mathrm{~min}$ was less than $1 \%$ and the rate of umbilical cord $\mathrm{pH}<7.0$ was less than $0.5 \%$. In the group with vaginal birth, $30 \%$ did not receive all five elements of the OASI care bundle. For instance, in $11 \%$ of deliveries the attending midwife was not previously certified to the care bundle. Likewise, $17 \%$ of deliveries took place without perineal support, while communication, visible perineum and hand on the fetal head were used in $90 \%$ of vaginal deliveries or more (Table 1 ).

The total OASI rate in vaginal delivery was less than $2 \%$. The risk of OASI for nulliparous women was almost fourfold the risk of multiparous women ( $R R=3.67$ (2.65.0) and $\mathrm{OR}=3.76$ (2.7-5.2)). Women with OVD had a 7.2 times higher risk of OASI compared with SVD (95\% $\mathrm{CI}=5.4-9.6 ; P<0.0001)$. Similarly, the subgroup of multiparous women with a previous CS had a rate of OASI of $4.9 \%$, which was 9.8 times higher compared with multiparous women without previous CS $(95 \% \mathrm{CI}=5.7-16.7$; $P<0.0001)$. The OASI rate was increased by nulliparity, epidural analgesia, dystocia treated with oxytocin, episiotomy, OVD, and higher birth weight. Birth weight increased the risk of OASI most prominently in nulliparous women. Standing birth position in nulliparous women was complicated by more cases with OASI (Table 2). The use of the single elements of the intervention together with the rate of OASI is shown in Table 3. Only very few cases occurred with just one specific element present and at the same time none of all other elements (less than 10 cases for four elements and only 71 cases for "Certification present"). For this reason, we only show data where just one element at a time was missing. Reduced rates were seen with visible perineum, hand on the fetal head and perineal support in the whole group and in the nulliparous group (Table 3 ).

Some of the elements showed association on the OASI rate, which was counter-intuitive, although the numbers were small. We carried out a subgroup analysis of the element "Certification", which in the univariate analysis showed a non-significant tendency towards a smaller risk of OASI in deliveries without certified midwife in both parity groups. The subgroup analysis showed that non-certified midwives took care of fewer women with a previous CS, as well as fewer with epidural and dystocia treated with oxytocin. Likewise, the birth weight was 
Table 1 Characteristics of vaginal deliveries

\begin{tabular}{|c|c|c|c|c|}
\hline & & $\begin{array}{l}\text { Nulliparous } \\
N=4384\end{array}$ & $\begin{array}{l}\text { Multiparous } \\
N=5999\end{array}$ & $\begin{array}{l}\text { Total } \\
N=10,383\end{array}$ \\
\hline $\begin{array}{l}\text { Age at delivery (years) }{ }^{a} \\
\text { Mean (SD) }\end{array}$ & & $27.8(4.2)$ & $31.3(4.3)^{* *}$ & $29.9(4.6)$ \\
\hline $\begin{array}{l}\text { Gestational age (days) } \\
\text { Mean (SD) }\end{array}$ & & $279(14)$ & $280(12)$ & $280(13)$ \\
\hline \multirow[t]{5}{*}{ Obstetrical factors N (\%) } & Spontaneous onset of delivery & $3105(71)$ & $4466(74)^{* *}$ & $7571(73)$ \\
\hline & Dystocia treated with Oxytocin & $704(16)$ & $326(5.4)^{* *}$ & $1030(9.9)$ \\
\hline & Epidural $^{a}$ & $1352(31)$ & $701(12)^{* *}$ & $2053(20)$ \\
\hline & OVD & $549(13)$ & $136(2.3)^{* *}$ & $685(6,6)$ \\
\hline & Episiotomy & $198(4.5)$ & $55(0.9)^{* *}$ & $253(2.4)$ \\
\hline \multirow[t]{6}{*}{ OASI care bundle N (\%) } & Communication & $4211(96)$ & $5327(89)^{* *}$ & $9538(92)$ \\
\hline & Perineum visible & $4114(94)$ & $5315(89)^{* *}$ & $9429(91)$ \\
\hline & Hand on fetal head & $4172(95)$ & $5698(95)$ & $9870(95)$ \\
\hline & Perineal support & $3800(87)$ & $4803(80)^{* *}$ & $8603(83)$ \\
\hline & Certification & $3922(89)$ & $5284(88)^{*}$ & $9206(89)$ \\
\hline & All five elements & $3263(74)$ & $3961(66)^{* *}$ & $7224(70)$ \\
\hline \multirow[t]{8}{*}{ Birth position ${ }^{\mathrm{b}} \mathrm{N}(\%)$} & Recumbent & $601(27)$ & $800(26)$ & $1401(26)$ \\
\hline & Semi-recumbent & $1272(56)$ & $1468(47)^{* *}$ & $2740(51)$ \\
\hline & Sitting upright / birthing chair & $11(0.5)$ & $17(0.5)$ & $28(0.5)$ \\
\hline & Squatting & $6(0.3)$ & $9(0.3)$ & $15(0.3)$ \\
\hline & Standing & $28(1.2)$ & $70(2.2)$ & $98(1.8)$ \\
\hline & All fours & $47(2.1)$ & $96(3.1)$ & $143(2.7)$ \\
\hline & Side lying & $157(6.9)$ & $366(11.7)^{* *}$ & $523(9.7)$ \\
\hline & Water birth & $144(6.4)$ & $303(9.7)^{* *}$ & $447(8.3)$ \\
\hline \multirow[t]{4}{*}{ Condition of the newborn baby N (\%) } & Apgar $<7 / 5$ min & $39(0.89)$ & $48(0.80)$ & $87(0.84)$ \\
\hline & $\mathrm{pH}<7.0^{\mathrm{c}}$ & $15(0.35)$ & $13(0.23)$ & $28(0.28)$ \\
\hline & $\mathrm{pH} 7.0-7.09^{c}$ & $174(4.1)$ & $128(3.8)$ & $302(3.4)$ \\
\hline & Missed pH & $121(2.8)$ & $221(3.7)^{*}$ & $342(3.4)$ \\
\hline Birth weight (grams) ${ }^{\mathrm{d}}$ Mean (SD) & & $3470(516)$ & $3654(512)^{* *}$ & $3576(522)$ \\
\hline
\end{tabular}

SD standard deviation, OVD operative vaginal delivery; ${ }^{a}$ information on age was missing in 391 cases and on epidural in 300 cases; percentages are calculated with the reduced denominator; ${ }^{b}$ registration of birth position started by December 11,$2017 ;{ }^{c}$ percentage calculated from total minus missed $\mathrm{pH}$; ${ }^{\mathrm{d}}$ singleton with gestational week $\geq 22+0$. Nulliparous women versus multiparous: *: $p<0.05 ;{ }^{* *}: p<0.01$. Herning Hospital, Denmark, 2016-2019

significantly smaller in the multipara group where the midwife taking care of the delivery was not certified (data not shown).

Presence of the whole care bundle (all five elements) was associated with a significant reduction in the OASI rate in the whole group and in nulliparous women. To investigate further the association of the whole care bundle, we compared the event "all five elements" being present and "not all five elements" present with the incidence of OASI. In the group of nulliparous, the incidence of OASI was $5.3 \%$ vs. $2.5 \%$ in favor of the presence of the whole care bundle. Similarly, in the case of OVD, the OASI was $15.6 \%$ compared to $7.7 \%$ in favor of all five elements present (Table 4).

In the univariate regression analysis nulliparity, higher birth weight, epidural, dystocia treated with oxytocin, episiotomy, and OVD were associated with a higher risk of OASI. In contrast, hand on the fetal head, perineal support and the OASI care bundle with all five elements present were associated with a lower risk (Table 5).

For evaluation in the full regression model, all significant variables were entered from the univariate regression analysis and the five individual elements of the care bundle. Thus, dystocia treated with oxytocin and epidural were no longer significant factors. Nulliparity and OVD remained as factors increasing the risk of OASI. Still, hand on the fetal head and perineal support were associated with a reduction of the OASI rate, when adjusted for all other factors except age and birth weight.

From the full regression model, we could calculate the potential benefit of using the care bundle. For instance, in a case of a nulliparous woman with a neonate weighing $3500 \mathrm{~g}$ giving birth with SVD the RR for OASI is 0.50 (CI: $0.49 ; 0.51)$ with use of hand on the fetal head together with perineal support against no use. Similarly, with a 


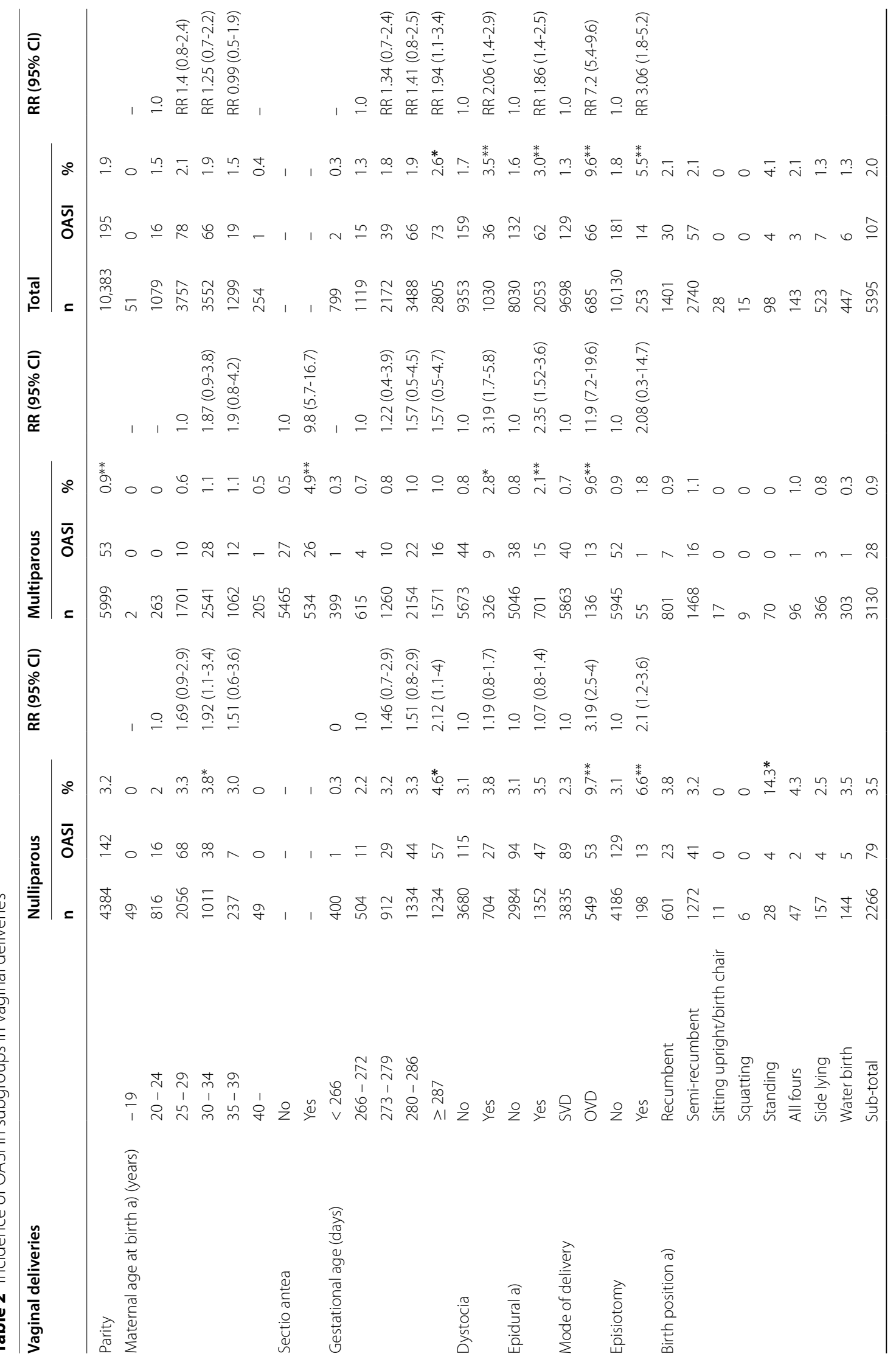




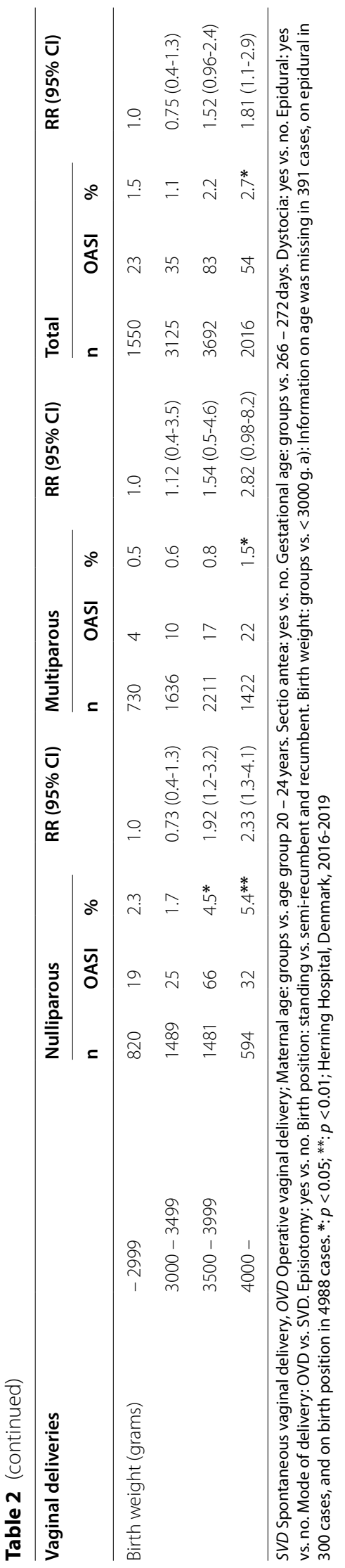


Table 3 Intervention - the single elements of the OASI care bundle and the incidence of OASI according to parity

\begin{tabular}{|c|c|c|c|c|c|c|c|c|c|c|c|c|}
\hline & \multicolumn{2}{|c|}{$\begin{array}{l}\text { Whole care bundle } \\
\text { present }\end{array}$} & \multicolumn{2}{|c|}{$\begin{array}{l}\text { Communication } \\
\text { present }\end{array}$} & \multicolumn{2}{|c|}{$\begin{array}{l}\text { Visible perineum } \\
\text { present }\end{array}$} & \multicolumn{2}{|c|}{$\begin{array}{l}\text { Hand on fetal } \\
\text { head present }\end{array}$} & \multicolumn{2}{|c|}{$\begin{array}{l}\text { Perineal support } \\
\text { present }\end{array}$} & \multicolumn{2}{|c|}{$\begin{array}{l}\text { Certification } \\
\text { present }\end{array}$} \\
\hline & No & Yes & No & Yes & No & Yes & No & Yes & No & Yes & No & Yes \\
\hline Total group (no.) & 3159 & 7224 & 845 & 9538 & 954 & 9429 & 513 & 9870 & 1780 & 8603 & 1177 & 9206 \\
\hline OASI (no.) & 72 & 123 & 12 & 183 & 21 & 174 & 28 & 167 & 47 & 148 & 14 & 181 \\
\hline$\%$ & 2.3 & $1.7 *$ & 1.4 & 1.9 & 2.2 & 1.8 & 5.5 & $1.7^{* *}$ & 2.6 & $1.7^{*}$ & 1.2 & 2.0 \\
\hline $\mathrm{RR}$ & 1.0 & 0.75 & 1.0 & 1.35 & 1.0 & 0.84 & 1.0 & 0.31 & 1.0 & 0.65 & 1.0 & 1.65 \\
\hline $95 \% \mathrm{Cl}$ & & $0.6-0.99$ & & $0.8-2.4$ & & $0.5-1.3$ & & $0.2-0.5$ & & $0.5-0.9$ & & $0.96-2.8$ \\
\hline Nulliparous (no.) & 1121 & 3263 & 173 & 4211 & 270 & 4114 & 212 & 4172 & 584 & 3800 & 462 & 3922 \\
\hline OASI (no.) & 59 & 83 & 9 & 133 & 15 & 127 & 23 & 119 & 38 & 104 & 11 & 131 \\
\hline$\%$ & 5.3 & $2.5^{* *}$ & 5.2 & 3.2 & 5.6 & $3.1 * *$ & 10.8 & $2.9 * *$ & 6.5 & $2.7^{* *}$ & 2.4 & 3.3 \\
\hline $\mathrm{RR}$ & 1.0 & 0.48 & 1.0 & 0.61 & 1.0 & 0.55 & 1.0 & 0.26 & 1.0 & 0.42 & 1.0 & 1.4 \\
\hline $95 \% \mathrm{Cl}$ & & $0.4-0.7$ & & $0.3-1.2$ & & $0.3-0.9$ & & $0.2-0.4$ & & $0.3-0.6$ & & $0.8-2.6$ \\
\hline Multiparous (no.) & 2038 & 3961 & 672 & 5327 & 684 & 5315 & 301 & 5698 & 1196 & 4803 & 715 & 5284 \\
\hline OASI (no.) & 13 & 40 & 3 & 50 & 6 & 47 & 5 & 48 & 9 & 44 & 3 & 50 \\
\hline$\%$ & 0.6 & 1.0 & 0.4 & 0.9 & 0.9 & 0.9 & 1.7 & 0.8 & 0.8 & 0.9 & 0.4 & 0.9 \\
\hline $\mathrm{RR}$ & 1.0 & 1.6 & 1.0 & 2.1 & 1.0 & 1.0 & 1.0 & 0.5 & 1.0 & 1.2 & 1.0 & 2.3 \\
\hline $95 \% \mathrm{Cl}$ & & $0.9-3.0$ & & $0.8-6.7$ & & $0.4-2.3$ & & $0.2-1.3$ & & $0.6-2.5$ & & $0.7-7.2$ \\
\hline
\end{tabular}

Element not present: All combinations of the elements of the care bundle except the element in question. Element present: All combinations of the elements in the care bundle including the element in question. $R R$ relative risk, $C l$ confidence interval. Yes vs. No: ${ }^{*}=p<0.05 .{ }^{* *}=p<0.01$. Herning Hospital, Denmark, 2016-2019

nulliparous woman giving birth to a neonate of $3500 \mathrm{~g}$ with OVD the RR is 0.65 (CI: $0.62 ; 0.68)$ against no use.

\section{Discussion}

\section{Main findings}

The emphasis on documenting process indicators on a person-level enabled us to gain novel information on the quality of obstetrical care concerning the relation between the individual elements and the outcome. Both hand on the fetal head and perineal support were associated with less OASI as did the 5 elements of the care bundle together. This finding was in alignment with previous interventional programs using similar care bundles [5-11]. The comprehensiveness of the birth cohort together with the intention of applying the five elements to all women constitute a sound ground for concluding that the intervention was associated with a benefit for women giving birth.

The OASI care bundle has been used in our department since 2013. In the original project, we reduced the OASI rate to $3.4 \%$ in nulliparous women delivering vaginally. The incidence was $3.2 \%$ in the present period from 2016 through 2019. Thus, corresponding with previous studies on robustness [12-14] the reduction was sustained for more than 7 years and cannot be attributed merely to focus or a hypothetical Hawthorne effect.

Risk factors for suffering OASI in our study as well as in other's were nulliparity, OVD and higher birth weight $[20,21]$. These well-established risk factors were present before and after a comparable, successful interventional program [22]. They may be modified in strength by an OASI care bundle but most likely, not to the extent that the risks disappear.

The tendency towards less OASI when a non-certified midwife took care of the delivery (see Table 3) was surprising but in fact logical. In subgroup analysis, it turned out that the group of non-certified midwives were taking care of less complicated births, which is in accordance with our policy. Furthermore, most were at the same time supervised by a certified midwife. Some of the other subgroups with absent single elements of the care bundle contained too small numbers to justify firm conclusions due to type II error (Table 4).

In almost all variables the rate of OASI was less in women who had the whole care bundle applied (see Table 4). The difference in the OASI rate within the multiparous women was too small to warrant any safe conclusion. On the other hand, the absolute rate of OASI in multiparous in our study was comparable to other studies $(7,11,13)$.

The use of episiotomy was associated with the risk of OASI (Table 1) but, mostly likely, not modified by the use of the bundle of care in this study (Table 4). Changing the concept is difficult about which clinical situations constitute an indication for episiotomy. In the recent EPITRIAL, one arm with routine care was compared with a study arm in which no episiotomy was to be performed [23]. The interim analysis surprisingly found that the rate 
Table 4 Intervention - use of the care bundle in different categories and the incidence of OASI

\begin{tabular}{|c|c|c|c|c|}
\hline & & $\begin{array}{l}\text { All } 5 \text { elements of care } \\
\text { bundle present } \\
\text { Total / OASI } \\
\text { No. / no. (\%) }\end{array}$ & $\begin{array}{l}\text { Not all } 5 \text { elements of care } \\
\text { bundle present } \\
\text { Total / OASI } \\
\text { No./ no. (\%) }\end{array}$ & $p$-value \\
\hline \multirow{2}{*}{ Parity } & Nulliparous & 3263 / $83(2.5)$ & $1121 / 59(5.3)$ & \multirow{2}{*}{$\begin{array}{l}\text { Nulliparous: } 0.001 * * \\
\text { Multiparous: } 0.15 \\
\text { Combined: } 0.046 *\end{array}$} \\
\hline & Multiparous & $3961 / 40(1)$ & $2038 / 13(0.6)$ & \\
\hline \multirow[t]{6}{*}{ Maternal age at birth a) (years) } & -19 & $41 / 0$ & $10 / 0$ & \multirow{6}{*}{$\begin{array}{l}\text { Combined: } 0.009^{* *} \\
\text { Linear trend: } 0.009^{* *}\end{array}$} \\
\hline & $20-24$ & $787 / 10(1.3)$ & $292 / 6(2.1)$ & \\
\hline & $25-29$ & $2671 / 46(1.7)$ & $1086 / 32(2.9)$ & \\
\hline & $30-34$ & $2425 / 41(1.7)$ & $1127 / 25(2.2)$ & \\
\hline & $35-39$ & $883 / 12(1.4)$ & $416 / 7(1.7)$ & \\
\hline & $40-$ & $184 / 1$ & $70 / 0$ & \\
\hline \multirow[t]{2}{*}{ Sectio antea } & No & $3549 / 21(0.6)$ & $1916 / 6(0.3)$ & \multirow{2}{*}{$\begin{array}{l}\text { No: } 0.16 \\
\text { Yes: } 0.61 \\
\text { Combined: } 0.15\end{array}$} \\
\hline & Yes & $412 / 19(4.6)$ & $122 / 7(5.7)$ & \\
\hline \multirow[t]{5}{*}{ Gestational age (days) } & $<266$ & $570 / 1(0.2)$ & $229 / 1(0.4)$ & \multirow{5}{*}{$\begin{array}{l}\text { Combined: } 0.046^{*} \\
\text { Linear Trend: } 0.046^{*}\end{array}$} \\
\hline & $266-272$ & $788 / 10(1.3)$ & $331 / 5(1.5)$ & \\
\hline & $273-279$ & $1498 / 23(1.5)$ & 674 / $16(2.4)$ & \\
\hline & $280-286$ & $2370 / 41(1.7)$ & $1118 / 25(2.2)$ & \\
\hline & $\geq 287$ & 1998 / $48(2.4)$ & $807 / 25$ (3.1) & \\
\hline \multirow[t]{2}{*}{ Dystocia treated with Oxytocin } & No & $6408 / 97(1.5)$ & $2945 / 62(2.1)$ & \multirow{2}{*}{$\begin{array}{l}\text { No: } 0.04^{*} \\
\text { Yes: } 0.29 \\
\text { Combined: } 0.046^{*}\end{array}$} \\
\hline & Yes & $816 / 26(3.2)$ & $214 / 10(4.7)$ & \\
\hline \multirow[t]{2}{*}{ Epidural a) } & No & $5475 / 82(1.5)$ & $2555 / 50(2)$ & \multirow{2}{*}{$\begin{array}{l}\text { No: } 0.001 * * \\
\text { Yes: } 0.1 \\
\text { Combined: } 0.001 * *\end{array}$} \\
\hline & Yes & $1659 / 41(2.5)$ & 394 / 21 (5.3) & \\
\hline \multirow[t]{2}{*}{ Mode of delivery } & SVD & $6706 / 83(1.2)$ & 2992 / 46 (1.5) & \multirow{2}{*}{$\begin{array}{l}\text { SVD: } 0.13 \\
\text { OVD: } 0.003^{* *} \\
\text { Combined: } 0.046^{*}\end{array}$} \\
\hline & OVD & $518 / 40(7.7)$ & 167 / 26 (15.6) & \\
\hline \multirow[t]{2}{*}{ Episiotomy } & No & 7044 / 114 (1.6) & 3086 / 67 (2.2) & \multirow{2}{*}{$\begin{array}{l}\text { No: } 0.053 \\
\text { Yes: } 0.56 \\
\text { Combined: } 0.046^{*}\end{array}$} \\
\hline & Yes & $180 / 9(5)$ & $73 / 5(6.8)$ & \\
\hline \multirow[t]{4}{*}{ Birth weight (grams) } & -2999 & 1061 / $18(1.7)$ & $489 / 5(1)$ & \multirow{4}{*}{$\begin{array}{l}\text { Combined: } 0.046^{*} \\
\text { Linear trend: } 0.046^{*}\end{array}$} \\
\hline & $3000-3499$ & $2178 / 18(0.8)$ & $947 / 17(1.8)$ & \\
\hline & $3500-3999$ & $2539 / 54(2.1)$ & 1153 / $29(2.5)$ & \\
\hline & $4000-$ & 1446 / $33(2.3)$ & $570 / 21(3.7)$ & \\
\hline
\end{tabular}

Categorical variables analyzed separately and combined. Continuous variables analyzed combined and with linear trend. a) Information on age was missing in 391 cases, on epidural in 300 cases, and on birth position in 4988 cases; $^{*}: p<0.05 ;{ }^{* *}: p<0.01$. SVD spontaneous vaginal delivery, OVD operative vaginal delivery. Herning Hospital, Denmark, 2016-2019

of episiotomy was equal in the two trial arms. A probable explanation for this may be that several of the indications for episiotomy are subjective and based on tradition and previous experience by midwives and doctors. The most effective way to implement a desired change in habits is likely a systematic approach with shared procedures and continuous audit, where data on processes and outcomes are monitored and provided for the staff together with education on the background for the change [23, 24]. This type of a systematic, organizational approach is a key point in the quality improvement work in our department, as well [9]. A new UK trial, "OASI2", will look more into scalable mechanisms of the implementation process of an OASI care bundle [25].

\section{Strengths and limitations}

A strength of this prospective follow-up study is that the OASI care bundle was implemented 7 years ago and is an integrated part of the department. The attending midwife carries out documentation of the use of the elements of the OASI care bundle as soon as possible after the birth. Adherence to the care bundle is monitored and feedback is provided for the staff of the process and outcome indicators. 
Table 5 Selected variables with univariate and full model regression analysis, odds ratio and adjusted odds ratio of perineal tear grade 3 and 4 (OASI). Data for the whole group of women except when otherwise specified

\begin{tabular}{|c|c|c|c|c|c|c|c|c|}
\hline \multirow[b]{2}{*}{ Variable } & \multicolumn{4}{|c|}{ Univariate analysis } & \multicolumn{4}{|c|}{ Full model analysis } \\
\hline & Coefficient (B) & $p$-value & Crude OR & $95 \% \mathrm{Cl}$ & Coefficient (B) & $p$-value & Adjusted OR & $95 \% \mathrm{Cl}$ \\
\hline Age at delivery ${ }^{\mathrm{a}}$ & -0.009 & 0.4 & & & - & - & & \\
\hline Parity (higher) & -1.3 & 0.001 & $0.27^{* *}$ & $0.2-0.4$ & -0.94 & 0.0001 & $0.39^{* *}$ & $0.3-0.6$ \\
\hline Dystocia treated with oxytocin & 0.7 & 0.001 & $2.09^{* *}$ & $1.5-3$ & -0.07 & 0.7 & 1.07 & $0.8-1.5$ \\
\hline Epidural & 0.6 & 0.001 & $1.86^{* *}$ & $1.4-2.5$ & 0.11 & 0.42 & 1.12 & $0.8-1.5$ \\
\hline Episiotomy & 1.2 & 0.001 & $3.22^{* *}$ & $1.8-5.6$ & 0.16 & 0.62 & 1.18 & $0.7-2.1$ \\
\hline OVD & 2.1 & 0.001 & $7.9^{* *}$ & $5.8-10.8$ & 1.7 & 0.0001 & $5.3^{* *}$ & $3.9-7.2$ \\
\hline Communication & 0.3 & 0.31 & 1.24 & $0.8-2.4$ & 0.34 & 0.83 & 1.41 & $0.9-2.7$ \\
\hline Visible perineum & -0.18 & 0.44 & 0.84 & $0.5-1.3$ & -0.06 & 0.862 & 0.95 & $0.6-1.5$ \\
\hline Hand on fetal head & -1.2 & 0.001 & $0.3^{* *}$ & $0.2-0.5$ & -0.78 & 0.001 & $0.46^{* *}$ & $0.3-0.8$ \\
\hline Perineal support & -0.4 & 0.01 & $0.65^{*}$ & $0.5-0.9$ & -0.78 & 0.0001 & $0.47^{* *}$ & $0.4-0.7$ \\
\hline Certification & 0.51 & 0.07 & 1.67 & $0.97-2.9$ & 0.07 & 0.2 & 1.47 & $0.9-2.6$ \\
\hline All five elements ${ }^{b}$ & -0.3 & 0.047 & $0.74^{*}$ & $0.6-0.99$ & -0.49 & 0.001 & $0.61^{* *}$ & $0.5-0.8$ \\
\hline Birth weight ${ }^{a}$ & 0.061 & 0.0001 & & & - & - & & \\
\hline \multicolumn{9}{|l|}{ Multiparous only: } \\
\hline Previous cesarean & 2.3 & 0.001 & $10.3^{* *}$ & $6-17.8$ & 1.9 & 0.001 & $6.8^{* *}$ & $4-12$ \\
\hline
\end{tabular}

OVD operative vaginal delivery. ${ }^{\mathrm{a}}$ age and birth weight by linear regression (Beta coefficient) and not included in the full model; all other logistic regression

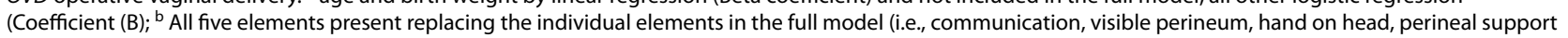
and certification), ${ }^{*}: p<0.05{ }^{* *}: p<0.01$. Herning Hospital, Denmark, 2016-2019

Standing birth position came out with a high OASI rate and, at the same time, constituted a challenge for the application of all five elements. In the present study, birth position in itself was not a significant factor for the risk of OASI after controlling for confounding factors. This is in alignment with other studies on risk factors for OASI [14, 26]. Choice of birth position only constitutes a potential limitation to the use of all elements of the care bundle during the last contractions before delivery. In fact, hand on the fetal head may be used in practically all birth positions. Informed choice of birth position lies with the delivering woman. Emphasis should be on supporting the woman as much as possible according to her preferences irrespective of the birth position.

The rate of asphyxia was similar compared with previous years and lower than the quality standards of $\leq 1.0 \%$, set by the Danish Quality Database for Birth [27]. Likewise, the rate of episiotomy remained low. Restrictive use of episiotomy is endorsed by FIGO rather than its routine use [28]. It may be that the acceptable rate should be as low as $10 \%$, although, the actual rate will, of course, reflect the baseline risk profile of the population. Besides imminent asphyxia, certain specific indications may stand the test in future research like episiotomy in OVD in nulliparous women [29], thereby, providing the ground for a common acceptance of the rate of episiotomy as an indicator of better quality of obstetrical care with optimum OASI rates [28].
The period where the elements of the intervention are applied (exposure time) should preferably be described in addition to presenting and analyzing the exposure and the outcomes in an interventional trial. In the present project, the time was not registered where the hands-on elements were in use because of the anticipated short period. This may constitute a weakness of the study. We advocate that the elements should only be applied during the last couple of contractions in order to avoid undue delay of the birth. In a case with suspected asphyxia, an expedite delivery will, of course, have first priority. In the beginning of the project, we noticed that hand on the fetal head and perineal support were applied for a longer period compared with later on in the project. This may still be an issue for untrained staff members. A too long application time of the hands may cause tiring of the hands besides possibly leading to an unwanted delay of the birth. For these reasons, we included this as a learning point for untrained midwives and doctors. A possible strength of these observations is an increased attention on being especially alert when the head is descending through the birth canal in order to avoid a sudden, uncontrolled fast delivery.

Another weakness in this study was the potential risk of residual confounding that was not taken into account by the statistical analysis. Causal relationships should be interpreted with caution because of the observational design, although, previously, we argued that the 
Bradford-Hill criteria support a causal relation between the OASI care bundle and a reduced risk of OASI [16]. The study was carried out in a single department and, therefore, external validity may be difficult to estimate. This may partly depend on the a priori attitude towards implementation of quality improvement work and the hands-on approach in a department.

\section{Interpretation}

We acknowledge that all the elements of OASI care bundles should be seen as integrated parts of the combined bundles $[11,18]$. In our case, five elements constitute the OASI care bundle. The first element concerning communication with the woman together with the fifth element concerning certification may be viewed as fundamental parts of a treaty between the mother and the midwife and/or the doctor. The second element of the care bundle concerning visible perineum is conditional for applying hands-on in the best possible way. Thus, the three elements may be perceived as facilitating the hands-on approach, where hand on the fetal head and perineal support constitute the active elements of the care bundle. This concept was supported by the findings in the present study and may add to the understanding of the effect of the care bundle and why it should be seen as a whole. Alternatively, as many elements should be applied as possible.

In the present study only around $70 \%$ of the women received all five elements of the OASI care bundle while $83 \%$ received perineal support (Table 1). Some women gave birth very quickly preventing the use of all elements. Some women preferred delivering in a position where not all elements could be applied. In a study by De Meutter only $73 \%$ of all deliveries received manual perineal protection [15]. This was partly ascribed to difficulties for specialists during OVD who applied perineal protection in less than half of the deliveries they attended. The explanation offered for this was emergencies with an urge to deliver the baby as fast as possible. Another suggestion was that professionals with more experience might have more difficulty to adapt to a new technique. Clinicians' perspectives on the use of an OASI care bundle were analyzed in a recent study, which found that adoption of the OASI care bundle relied on several components [30]. Among these were the initial implementation strategy in a department, personal values concerning the possible need for changing behavior by the clinician and different perceptions of what women want. Since it is not feasible to apply all elements of an OASI care bundle in all deliveries, we find it important to document the use of each element, especially when analysis is carried out for comparative reasons.
In fact, the lack of analyzing per protocol may partly explain that no difference was found in the risk of OASI in the RCTs between the hands-on versus hands-off techniques. Three recent meta-analyses on randomized trials [31-33] include five RCT's with data on OASI incidence [34-38]. When the intention-to-treat analyses in these trials are combined with defining the intervention in the hands-off arm as "hands-poised", the treatment that was actually provided in each case becomes obscured, insofar the 'hands-poised' method allows for using elements from the hands-on method. It may be that treatments in both randomization arms in the RCTs were in reality quite similar, thus, explaining that no difference in outcome was found. We propose that the elements of the interventions that are used should be documented on a person-level, also in RCT's.

Another issue in the discussion between hands-off versus hands-on is about the definition of the hands-on intervention. In the three larger RCT's the supposed aim in the hands-on technique was to "increase flexion of the head" $[34,35]$ or "maintaining the flexion of the head" [38]. We are aware that the fetal head is flexed on its way through the birth canal. However, the head extends through the introitus when the head is crowning in the final part of the delivery. The distinction between flexing and extending the head is crucial and should be made clear in future work and meta-analyses in this field.

\section{Conclusions}

The present study confirms that a lesser risk of OASI is associated with use of both hand on the fetal head and perineum. We suggest documenting on a person-level the specific elements of the intervention aimed at reducing the incidence of OASI. Future studies should focus on the question of flexion or extension of the head of the child during the passage of the introitus in order to achieve a further reduction in OASI.

\section{Abbreviations \\ OASI: Obstetric anal sphincter injury; CS: Caesarean section; SVD: Spontane- ous vaginal delivery; OVD: Operative vaginal delivery; RR: Relative risk; Cl: Confidence interval.}

\section{Acknowledgements}

We are grateful to all midwives, doctors and management of our department for dedicated support to continuous quality improvement initiatives including this project on reducing the risk of OASI.

\section{Authors' contributions}

CA: Project development, Data collection, Manuscript editing, Final approval. JB: Project development, Manuscript editing, Final approval. FL: Project development, Data analysis, Statistics, Manuscript editing, Final approval. OR: Project development, Data analysis, Manuscript writing, Final approval. AY: Project development, Data collection, Manuscript editing, Final approval.

\section{Funding}

No funding received. 


\section{Availability of data and materials}

The anonymized data that support the findings of this study are available from the corresponding author upon reasonable request.

\section{Declarations}

\section{Ethics approva}

Approval for the present study from the local Ethics Committee (Mid-Jutland Region) was deemed not relevant by the Committee, since approval is not required for quality improvement work according to Danish Law (Law No 1083, \$14, September 15, 2017, On Ethics in Research in Healthcare projects), October 11,2020. Approval from each patient to participate in quality improvement work is not necessary according to The Danish Health Law, amendment no 430, May 3, 2017, §42d, 2-2. We obtained approval from the department and hospital managements to retrieve the relevant anonymized data for the present study.

\section{Consent for publication}

N/A.

\section{Competing interests}

The authors declare that they have no competing interests.

Received: 10 February 2021 Accepted: 9 November 2021 Published online: 18 November 2021

\section{References}

1. Desseauve D, Proust S, Carlier-Guerin C, Rutten C, Pierre F, Fritel X. Evaluation of long-term pelvic floor symptoms after an obstetric anal sphincter injury (OASI) at least one year after delivery: a retrospective cohort study of 159 cases. Gynécol Obstét Fertil. 2016;44:385-90. https://doi.org/10. 1016/j.gyobfe.2016.05.007.

2. Halle TK, Salvesen KÅ, Volløyhaug I. Obstetric anal sphincter injury and incontinence 15-23 years after vaginal delivery. Acta Obstet Gynecol Scand. 2016. https://doi.org/10.1111/aogs.12898.

3. https://masic.org.uk/. Accessed 6 Oct 2021

4. Johansson C, Finnbogadóttir. First-time mothers' satisfaction with their birth experience - cross-sectional study. Midwifery. 2019;79:102540. https://doi.org/10.1016/j.midw.2019.102540.

5. Laine K, Pirhonen T, Rolland R, Pirhonen J. Decreasing the incidence of anal sphincter tears during delivery. Obstet Gynecol. 2008;111:1053-7. https://doi.org/10.1097/AOG.0b013e31816c4402.

6. Hals E, Øian P, Pirhonen T, et al. A multicenter interventional program to reduce the incidence of anal sphincter tears. Obstet Gynecol. 2010;116:901-8. https://doi.org/10.1097/AOG.0b013e3181eda77a.

7. Laine K, Skjeldestad FE, Sandvik L, Staff AC. Incidence of obstetric anal sphincter injuries after training to protect the perineum: cohort study. BMJ Open. 2012;2:e001649. https://doi.org/10.1136/bmjop en-2012-001649.

8. Leenskjold S, Høj L, Pirhonen J. Manual protection of the perineum reduces the risk of obstetric anal sphincter ruptures. Dan Med J. 2015;62(5):A5075 PMID: 26050831.

9. Rasmussen OB, Yding A, Anhøj J, Andersen CS, Boris J. Reducing the incidence of obstetric sphincter injuries using a hands-on technique: an interventional quality improvement project. BMJ Qual Improv Rep. 2016;5:u217936.w7106. https://doi.org/10.1136/bmjquality.u217936. w7106.

10. Borrman MJ, Davis D, Porteous A, Lim B. The effects of a severe perineal trauma prevention program in an Australian tertiary hospital: an observational study. Women Birth. 2019. https://doi.org/10.1016/j.wombi.2019. 07.301.

11. Gurol-Urganci I, Bidwell P, Sevdalis N, et al. Impact of a quality improvement project to reduce the rate of obstetric anal sphincter injury: a multicentre study with a stepped-wedge design. BJOG. 2020. https://doi. org/10.1111/1471-0528.16396.

12. Fretheim A, Odgaard-Jensen J, Røttingen J-A, Reinar LM, Vangen $S$, Tanbo T. The impact of an intervention programme employing a hands-on technique to reduce the incidence of anal sphincter tears: interrupted time-series reanalysis. BMJ Open. 2013;3:e003355. https:// doi.org/10.1136/bmjopen-2013-003355.

13. Basu M, Smith D. Long-term outcomes of the Stop Traumatic OASI Morbidity Project (STOMP). Int J Gynecol Obstet. 2018:1-5. https://doi. org/10.1002/ijgo.12565.

14. Selmer-Olsen T, Nøhr EA, Tappert C, Eggebø TM. Incidence and risk factors for obstetric anal sphincter ruptures, OASIS, following the introduction of preventive interventions. A retrospective cohort study from a Norwegian hospital 2012-2017. Sex Reprod Healthc. 2019;22. https:// doi.org/10.1016/j.srhc.2019.100460.

15. De Meutter L, van Heesewijk AD, van der Woerdt-Eltink I, de Leeuw JW. Implementation of a perineal support programme for reduction of the incidence of obstetric anal sphincter injuries and the effect of non-compliance. Eur J Obstet Gynecol Reprod Biol. 2018;230:119-23. https://doi.org/10.1016/j.ejogrb.2018.09.021.

16. Rasmussen OB, Yding A, Lauszus F, Andersen CS, Anhøj J, Boris J. Importance of individual elements for perineal protection in childbirth: an interventional, prospective trial. Am J Perinatol Rep. 2018;8:e289-94. https://doi.org/10.1055/s-0038-1675352.

17. Laganà AS, Terzic M, Dotlic J, Sturlese E, Palmara V, Retto G, et al. The role of episiotomy in prevention of genital lacerations during vaginal deliveries - results from two European centers. Ginekol Pol. 2015;86:168-75. https://doi.org/10.17772/gp/2058.

18. http://www.ihi.org/resources/Pages/ImprovementStories/WhatlsaBun dle.aspx - Accessed 6 Oct 2021.

19. Sultan $A H$. Editorial: obstetrical perineal injury and anal incontinence. Clin Risk. 1999;5:193-6.

20. Vathanan $\mathrm{V}$, Ashokkumar O, McAree T. Obstetric anal sphincter injury risk reduction: a retrospective observational analysis. J Perinat Med. 2014;42(6):761-7. https://doi.org/10.1515/jpm-2013-0269.

21. Meister MRL, Cahill AG, Conner SN, Woolfolk CL, Lowder JL. Predicting obstetric anal sphincter injuries in a modern obstetric population. Am J Obstet Gynecol. 2016;215(310):e1-7. https://doi.org/10.1016/j.ajog. 2016.02.041.

22. Stedenfeldt M, Øian P, Gissler M, Blix E, Pirhonen J. Risk factors for obstetric anal sphincter injury after a successful multicentre interventional programme. BJOG. 2014;121:83-91. https://doi.org/10.1111/ 1471-0528.12274.

23. Sagi-Dain L, Bahous R, Caspin O, Kreinin-Bleicher I, Gonen R, Sagi S. No episiotomy versus selective lateral/mediolateral episiotomy (EPITRIAL): an interim analysis. Int Urogynecol J. 2017. https://doi.org/10.1007/ s00192-017-3480-7.

24. Franchi M, Parissone F, Lazzari C, Garzon S, Laganà AS, Raffaelli R, et al. Selective use of episiotomy: what is the impact on perineal trauma? Results from a retrospective cohort study. Arch Gynecol Obstet. 2020;301:427-35. https://doi.org/10.1007/s00404-019-05404-5.

25. Jurczuk M, Bidwell P, Gurol-Urganci I, van der Meulen J, Sevdalis N, Silverton $L$, et al. The OASI care bundle quality improvement project: lessons learned and future direction. Int Urogynecol J. 2021. https:// doi.org/10.1007/s00192-021-04786-y.

26. Smith LA, Price N, Simonite V, Burns EE. Incidence of and risk factors for perineal trauma: a prospective observational study. BMC Pregnancy Childbirth. 2013;13:59. https://doi.org/10.1186/1471-2393-13-59.

27. https://www.sundhed.dk/content/cms/66/4666_aarsrapport-dkf-20172018-hovedrapport-samt-bilag-12.pdf, Accessed 6 Oct 2021.

28. Nassar AH, Visser GHA, Ayres-de-Campos D, Rane A, Gupta S, For the FIGO MOtherhood and Newborn Health Committee. FIGO statement: restrictive use rather than routine use of episiotomy. Int J Gynecol Obstet. 2019;146:17-9. https://doi.org/10.1002/ijgo.12843.

29. Bergendahl S, Ankarcrona V, Leijonhufvud §, Hesselman S, Karlström $S$, Kallner HK, et al. Lateral episiotomy versus no episiotomy to reduce obstetric anal sphincter injury in vacuum-assisted delivery in nulliparous women: study protocol on a randomized controlled trial. BMJ Open. 2019;9:e025050. https://doi.org/10.1136/bmjopen-2018-025050.

30. Bidwell P, Thakar R, Gurol-Urganci I, et al. Exploring clinicians' perspectives on the "obstetric anal sphincter injury care bundle" national quality improvement programme: a qualitative study. BMJ Open. 2020;10:e035674. https://doi.org/10.1136/mbjopen-2019-035674

31. Bulchandani S, Watts $E$, Sucharitha A, Yates D, Ismail KM. Manual perineal support at the time of childbirth: a systematic review and meta-analysis. BJOG. 2015;122:1157-65. https://doi.org/10.1111/1471-0528.13431. 
32. Aasheim V, Nilsen ABV, Reinar LM, Lukasse M. Perineal techniques during the second stage of labour for reducing perineal trauma. Cochrane Database Syst Rev. 2017;6:CD006672. https://doi.org/10.1002/14651858. CD006672.pub3.

33. Pierce-Williams RAM, Saccone G, Berghella V. Hands-on versus hands-off techniques for the prevention of perineal trauma during vaginal delivery: a systematic review and meta-analysis of randomized controlled trials. J Maternal-Fetal Neonatal Med. 2019. https://doi.org/10.1080/14767058. 2019.1619686.

34. McCandlish $\mathrm{R}$, Bowler $\mathrm{U}$, van Asten $\mathrm{H}$, et al. A randomized controlled trial of care of the perineum during second stage of normal labour. BJOG. 1998;105:1262-72. https://doi.org/10.1111/j.1471-0528.1998.tb10004.x.

35. Mayerhofer K, Bodner-Adler B, Bodner K, et al. Traditional care of the perineum during birth. A prospective, randomized, multicenter study of 1,076 women. J Reprod Med. 2002;47:477-82 PMID: 12092017.

36. Da Costa ASC, Riesco MLG. A comparison of "hands off" versus "hands on" techniques for decreasing perineal lacerations during birth. J Midwifery
Womens Health. 2006;51:106-11. https://doi.org/10.1016/j.jmwh.2005.10 017.

37. Foroughipour A, Firuzeh F, Ghahiri A, Norbakhsh V, Heidan T. The effect of perineal control with hands-on and hand-poised methods on perineal trauma and delivery outcome. J Res Med Sci. 2011;16(8):1040-6 PMID: 22279480. PMC3263081.

38. Rezaei R, Saatsaz S, Chan YH, Nia HS. A comparison of the "hands-off" and "hands-on" methods to reduce perineal lacerations: a randomised clinical trial. J Obstet Gynecol India. 2014;64(6):425-9. https://doi.org/10.1007/ s13224-014-0535-2.

\section{Publisher's Note}

Springer Nature remains neutral with regard to jurisdictional claims in published maps and institutional affiliations.
Ready to submit your research? Choose BMC and benefit from:

- fast, convenient online submission

- thorough peer review by experienced researchers in your field

- rapid publication on acceptance

- support for research data, including large and complex data types

- gold Open Access which fosters wider collaboration and increased citations

- maximum visibility for your research: over 100M website views per year

At BMC, research is always in progress.

Learn more biomedcentral.com/submissions 